Development \& validation of scientific video vignettes to promote perception of authentic science in student laboratories

\title{
Stamer, Insa
}

2020-04-02

Stamer , I , Pönicke , H , Tirre , F , Laherto , A , Höffler , T , Schwarzer , S \& Parchmann , I 2020 , ' Development \& validation of scientific video vignettes to promote perception of authentic science in student laboratories ' , Research in Science \& Technological Education , vol. 38 , no. 2 , pp. 168-184 . https://doi.org/10.1080/02635143.2019.1600491

http://hdl.handle.net/10138/322186

https://doi.org/10.1080/02635143.2019.1600491

unspecified

acceptedVersion

Downloaded from Helda, University of Helsinki institutional repository.

This is an electronic reprint of the original article.

This reprint may differ from the original in pagination and typographic detail.

Please cite the original version. 
This is Authors' Accepted Manuscript of an article published by Taylor \& Francis in Research in Science \& Technological Education (published online 26 Apr 2019). Available at: https://doi.org/10.1080/02635143.2019.1600491

Citation to the published article:

Stamer, I., Pönicke, H., Tirre, F., Laherto, A., Höffler, T., Schwarzer, S., \& Parchmann, I. (2020). Development \& validation of scientific video vignettes to promote perception of authentic science in student laboratories. Research in Science \& Technological Education, 38(2), 168-184. DOI: 10.1080/02635143.2019.1600491

\title{
Development \& validation of scientific video vignettes to promote perception of authentic science in student laboratories
}

\author{
Insa Stamer ${ }^{a^{*}}$, Hanno Pönicke ${ }^{a}$, Frederike Tirre ${ }^{b}$, Antti Laherto ${ }^{c}$, Tim Höffler ${ }^{a}$, \\ Stefan Schwarzer ${ }^{\mathrm{d}}$ and Ilka Parchmann ${ }^{\mathrm{a}}$
}

${ }^{a}$ Chemistry Education, Leibniz Institute for Science and Mathematics Education, Kiel, Germany; ${ }^{b}$ Cluster of Excellence "The Future Ocean", Kiel University, Kiel, Germany; 'Department of Education, University of Helsinki, Helsinki, Finland; ${ }^{d}$ Chemistry Education, LudwigMaximilians-University, Munich, Germany

Insa Stamer

Chemistry Education

Leibniz Institute for Science and Mathematics Education

Olshausenstraße 62

24118 Kiel

e-mail: stamer@ipn.uni-kiel.de

\begin{abstract}
Background: Many students have incomplete or incorrect perceptions of science and scientists. These simplified images, mediated by media or influential agents of socialisation, result in common stereotypes. Especially for occupational choices it is important to convey an authentic image about science and scientists.

Purpose: One manner to convey an authentic image and thus the aim of this study is the development and validation of scientific videos including collected activities of scientists.

Program description: Professors were interviewed regarding their typical scientific activities. This was followed by the development of a questionnaire which was answered by junior scientists. Authentic scientific videos were developed and finally validated in a science lab for school-students based on qualitative and quantitative results.

Sample: 92 junior scientists answered the questionnaire and eight professors and 96 students ( 31 girls and 65 boys; grade 10 to 13 ) were interviewed.

Design and methods: The scientists were surveyed before the development of the videos. The RIASEC $+\mathrm{N}$ model was used to categorise the collected activities of scientists. Finally, students were interviewed for the video validation.

Results: A number of different scientific activities of each RIASEC $+\mathrm{N}$ dimension could be detected, which were then integrated into four videos. The interviewed students who watched those videos successfully identified all of the activities.
\end{abstract}


Conclusion: The working day of scientists contains more than stereotypical aspects and wellconsidered/planned videos are one suitable option to promote an authentic overview about science and scientists.

Keywords: Scientific videos, authenticity, out-of-school learning environments, RIASEC+N model

\section{Introducation}

To bring order into the complexity of reality people tend to categorize when dealing with large blocks of information. This results in the formation of prejudices and stereotypes through simplifications and generalisations (Tintori 2017).

Media and influential agents of socialisation such as parents or peers have a great impact on young people's impressions and opinions (Archer et al., 2014). This often causes people to adopt those values and beliefs which lead to a multitude of stereotypical categories: regional, ethnic, sexes and even occupational. One occupational and quite common example is about the scientist often described as a "man in a white lab coat with a beard". He is presumed to work in a laboratory all day, is intelligent, always busy and his work is possibly dangerous (Höttecke, 2004, p. 264). Likewise, other studies identified different stereotypical images of scientists. Tintori (2017, p. 4) describes scientific stereotypes as follows: "scientists are smart, hardworking, eccentric, workaholic men. The image conveys an idea of social isolated and of an "unbalanced" life, without family and children, friends, hobbies or interests". In earlier studies Solomon et al. (1994) identified seven different stereotypical student perceptions of scientists: The cartoon scientist looks like a slightly scatter brained, crazy-haired man who conducts dangerous experiments; the vivisectionist who experiments on living animals is cruel and cold; the authoritative scientist is all knowing and performs experiments not to learn but to teach; the technologist helps society by developing useful artefacts; the entrepreneur views science as a field to compete in. Students also generally consider the teacher and themselves as scientists. In their stereotypical form, teachers are scientists who relay their knowledge by showing students commonly known experiments, while students see themselves as a kind of apprentice scientists.

In summary, many different descriptions of scientists exist which partially stem from misconceptions and partially from conceptions based on simplifications that can be used as a foundation for a holistic/authentic perception of scientists (Posner et al., 1982; Cohen et al., 2017; Flaig et al., 2018). While many of these stereotypes of scientists are partly true, they all lack the diversity of today's scientists and their activities and therefore cannot convey an authentic view. A scientist may wear a lab coat and work in a laboratory but probably not all day. It is important not to emphasize one aspect of an occupation or leave out another to promote the field. Some people may identify with a certain stereotypical aspect (Setterlund \& Niedenthal, 1993; Hannover \& Kessels, 2002), allowing them to follow a scientific career, but some require a diversified image. In general, it is always important to get the most authentic impression of an occupation before choosing it.

Students can get an authentic insight into science through out-of-school learning environments. Out-of-school learning environments include, for example, museums, science centres and planetariums and are often connected to scientific institutions like universities. Mostly they are characterised by new technologies and advanced learning techniques designed for informal settings (Popli, 1999; Godin \& Gingras, 2000). They were designed so entire school classes or single interested students could visit to get an insight into authentic science or possibly university life. Braund and Reiss (2006) formulated the following five ways in which out-ofclassroom contexts can add to and improve science learning: the development and integration 
of concepts; the promotion of constructive attitudes towards school sciences; improved social outcomes through collaborative work and responsibility for learning, as ascertained by Ulriksen et al. (2010); access to rare materials and to "big" science; the extended, authentic practical work. These last three points comprise the contact between school students and institutes of higher education. In Germany, so-called "student laboratories", special out-of-school learning environments, are already well established. These laboratories are often connected to universities equipped with modern technology and focused on current research topics. School classes regularly visit over 300 of these labs and individual students sometimes experience what it's like to be a scientist (Glowinski and Bayrhuber, 2011). Similar to what Braund and Reiss have done for out-of-school learning environments, Euler (2005) summarised eight student laboratories goals: The most relevant of these in the context of this study are: contact with modern science through experience-based access to scientific processes; creation of a stimulating learning environment in which students are actively confronted with authentic scientific problems (preferably connected to the students' everyday experiences); providing experiences in various scientific activities and career pathways; providing personal contact with scientists.

Overall, it is obvious that the goals formulated by Braund and Reiss (2006) and Euler (2005) overlap. For example, they both focus on students' contact with authentic, actual science. The goals formulated for student laboratories (Euler, 2005) are of critical importance because incorrect perceptions and expectations not only hinder students from choosing the right career path but they result in students dropping out of university. Thus, an authentic insight into science might provide a solution to this problem.

\section{Authentic insight into science through videos}

Studies proposed different ways to convey authentic science over the years - for example, helping students learn scientists' practices and attitudes (Edelson, Gordin, \& Pea, 1999) by dealing with everyday problems for lifelong learning (Edelson, 1998; Lee \& Songer, 2003) or conveying an authentic perception of science through interaction between students and scientists (Lee \& Songer, 2003; Pea, 1994). Woods - McConney et al. (2013) summarised why an authentic mediation of science is important: it improves students' attitudes towards science and scientific careers (Coll \& Paku, 2011) as well as the engagement and interest in science. Another important aspect for an authentic learning situation is the motivating effect (Goldman et al., 1998).

In an interview with teachers and headmasters, Schmidt, Di Fuccia and Ralle (2011) found that teaching professionals felt that insights into authentic scientific environments and contact with real researchers could improve children's understanding of scientific careers. But they also doubted whether scientists would be able to accurately convey their occupation to students and to ensure that student laboratories are authentic scientific environments. Furthermore, due to lack of time it is usually not possible for the scientists to regularly guide the school students in their laboratories or to be present in the learning environments. One could address this lack of authenticity by adding videos to the student laboratories that show the scientists in their normal working environment. Thereby, the students can watch the scientists' actual work instead of having to follow the scientist's narration which might focus on just the highlights of his or her work rather than portraying a holistic view. Instead of only working on adjusted experiments from the student laboratory (Affeldt et al., 2015), they also get to view videos of the actual projects the scientists are working on. Thus, there is a specific, necessary guidance conveying the complexity of authentic inquiry. Importantly, Goldman et al. (1994) have already shown that authentic videos about science can motivate students to solve scientific problems. Students were shown a video with a scientific real-world problem and then asked to find a solution. Afterwards, the video was continued showing the scientist' solution. 


\section{Framework and aims of this project}

The main goal of this project is the development and validation of scientific video vignettes which convey authentic insights into the daily work of scientists. Therefore, this article is divided into two parts as it presents the findings of two sub-studies: a) collection of information on what a scientist's typical day looks like and b) development and validation of videos. For the first sub-study, professors were interviewed about their work activities. Typical activities of scientists were classified into dimensions for a questionnaire based on the answers. A final questionnaire was given to the scientists to validate whether the chosen activities are actually typical. The method, results and discussion are shown in the following section. Videos showing those typical activities were produced based on the results of this first sub-study. The validation through a Think-Aloud-study and interviews with students who watched the videos is presented after a short presentation of the developed videos. The corresponding results are shown in the Study 2 section.

This leads to the following two research questions:

- "What are the typical activities of scientists?"

- "Do the students perceive the diversity of science, or rather scientific activities, in the videos?"

In order to assess effects of the videos, the collected typical activities of scientists should be sorted into dimensions of a suitable model. The RIASEC $+\mathrm{N}$ model described in this section was chosen based on this assessment. The original RIASEC model was developed by Holland for vocational choices (Holland, 1963; Holland, 1997). In this model every letter represents a specific professional field as shown in Table 1. Further studies by Armstrong et al. (2008) showed that scientists originally placed in the investigative dimension by Holland also practise activities in the six other dimensions. Hence, Dierks et al. (2014) modified the RIASEC model to measure the students' interests in scientific activities. Based on empirical analyses, a seventh dimension "networking (N)" was introduced which contained the field of activities in which scientists are working together. Subsequently, Wentorf et al. (2015) interviewed students and scientists in order to measure the perception regarding typical scientific activities. Table 1 shows the description of the dimensions with corresponding example activities. Only the selfperception of scientists regarding their own work was required as this study aims to develop authentic scientific videos.

Table 1. Overview of the RIASEC model by Holland (1997) and the adapted RIASEC+N model by Wentorf et al. (2015)

\begin{tabular}{|l|l|l|l|l|}
\hline Dimension & Acronym & Type of Activity & $\begin{array}{l}\text { Example Profession } \\
\text { (by Holland) }\end{array}$ & $\begin{array}{l}\text { Example Activity of } \\
\text { Scientists } \\
\text { (by Wentorf et al.) }\end{array}$ \\
\hline Realistic & $\mathrm{R}$ & handicraft & carpenter & $\begin{array}{l}\text { performing } \\
\text { measurements }\end{array}$ \\
\hline Investigative & $\mathrm{I}$ & intellectual & scientist & interpreting data \\
\hline Artistic & $\mathrm{A}$ & creative & actor & $\begin{array}{l}\text { developing research } \\
\text { ideas }\end{array}$ \\
\hline Social & $\mathrm{S}$ & helping & teacher & supervising students \\
\hline Enterprising & $\mathrm{E}$ & managing & politician & $\begin{array}{l}\text { guiding } \\
\text { groups }\end{array}$ \\
\hline $\begin{array}{l}\text { Conventiona } \\
1\end{array}$ & $\mathrm{C}$ & $\begin{array}{l}\text { administratively; } \\
\text { meticulous }\end{array}$ & secretary & $\begin{array}{l}\text { doing administrative } \\
\text { tasks }\end{array}$ \\
\hline
\end{tabular}




\begin{tabular}{|l|l|l|l|l|}
\hline Networking & $\mathrm{N}$ & collaborating & - & $\begin{array}{l}\text { exchanging with } \\
\text { scientists from other } \\
\text { universities }\end{array}$ \\
\hline
\end{tabular}

\section{Principles of the study and results}

\section{Sub-study 1: Typical activities of scientists}

Before the video development could start, it was necessary to ascertain which tasks the work of scientists generally contains and how to categorize them. In order to answer those questions we used qualitative and quantitative instruments, i.e., interviews and a questionnaire. During the qualitative study (Laherto et al., 2018), eight university professors of a Collaborative Research Centre (CRC) focusing on nano research were interviewed about their daily work. Each interview took approximately 60 minutes and was carried out by two interviewers.

Among other things, the professors were asked the following during the interviews:

"Please describe the process of one of your nano related research projects and its organisational and scientific processes."

The scientists then listed typical and relevant activities ranging from the development of new research ideas to presenting results. However, the interviewed professors not only spoke about their own activities, but also about activities such as performing measurements, of their researching doctoral and post-doctoral students. Overall, a broad spectrum of activities was collected. Therefore, the interviews fit our intentions and we decided to re-analyse them. The scientists mentioned activities from all RIASEC+N dimensions (Table 2). Thus, the model also seemed suitable for our purposes and was consequently used for the presented study. The interviews were transcribed and then analysed using the framework of qualitative content analysis by Mayring (2008). We used a deductive process in which the quotes or rather the activities were sorted into categories according to the RIASEC $+\mathrm{N}$ model (Dierks, Höffler, Parchmann, 2014; Wentorf et al., 2015; see above). The evaluation of the interviews conducted by three different evaluators resulted in a Fleiß's kappa value of .83 and Cohen's kappa values between .76 and .96 which confirm a good to very good interrater agreement.

Table 2. Example quotes of scientific professors about their own work sorted into RIASEC+N dimensions.

\begin{tabular}{|l|l|l|}
\hline Dimension & Mentions & Quote \\
\hline R Realistic & 56 & $\begin{array}{l}\text { "If you do experiments, you have to be good at operating the } \\
\text { instruments ..." }\end{array}$ \\
\hline I Investigative & 44 & $\begin{array}{l}\text { "... [we work with theoreticians sometimes] to explain these } \\
\text { results." }\end{array}$ \\
\hline A Artistic & 40 & "... you need to find good relevant scientific questions." \\
\hline S Social & 7 & "... also discussing with my students and Ph.D. students ..." \\
\hline E Enterprising & 18 & "The money procedures, yes, I think that's fairly general." \\
\hline C Conventional & 5 & $\begin{array}{l}\text { "... two people together, synchrotron-based techniques } \\
\text { usually require working in 24-hour shifts, so we typically } \\
\text { need , a measurement team of three to four researchers to } \\
\text { run the experiment continuously for a week or two and..." }\end{array}$ \\
\hline
\end{tabular}




\begin{tabular}{|l|l|l|}
\hline N Networking & 48 & $\begin{array}{l}\text { "... I'm not saying that a chemist or physicist cannot } \\
\text { produce nano materials and study them, but it helps to have } \\
\text { this more interdisciplinary approach. And often it helps to } \\
\text { have cooperation." }\end{array}$ \\
\hline
\end{tabular}

Based on the gathered and sorted answers of the professors, we finally developed a questionnaire by using the RIASEC $+\mathrm{N}$ categories as dimensions: the dimension Realistic includes activities that require you to work with your hands such as executing measurements or performing experiments; Investigative includes activities concerning both literature and data, for example reading research literature or interpreting experimental data as Wentorf et al. (2015) mentioned; Artistic also consists of two aspects: the first is more creative such as developing new research ideas and the second aspect is more aesthetic such as creating scientific posters (Wentorf, 2016); the dimension Social is composed of teaching and supporting activities such as supervising university students; the Enterprising dimension includes activities regarding finances such as raising funds for research projects; Conventional consists of activities which are meticulous such as writing down measurement data and the Networking dimension includes collaborative activities such as meeting colleagues from other departments.

A four-point Likert scale from strongly agree (1) to strongly disagree (4) was chosen to determine the importance of the different activities - if the activities which were sorted into the RIASEC $+\mathrm{N}$ dimensions are typical for scientists or not. Example items from the questionnaire are shown in Table 3.

Table 3. Example items of the RIASEC+N dimensions.

\begin{tabular}{|l|l|}
\hline & $\begin{array}{l}\text { Example Item } \\
\text { The regular everyday work of a scientist involves... }\end{array}$ \\
\hline R & performing measurements. \\
\hline I & interpreting experimental data. \\
\hline A & designing new research approaches. \\
\hline S & giving lectures and seminars for university students. \\
\hline E & writing a financial plan for their research projects. \\
\hline C & monitoring ongoing reactions or measurements. \\
\hline N & working together in interdisciplinary projects. \\
\hline
\end{tabular}

Afterwards, 51 junior scientific researchers of different fields (e.g. chemistry, physics, pharmaceutical and material science) answered the questionnaire. Because of the low reliabilities of the dimensions Realistic, Investigative and Artistic, we optimised these dimensions. For the Realistic dimension we removed one item, for the dimension Investigative we removed three items and developed five new items, and for the Artistic dimension we removed one item and developed three new items. For the Investigative dimension we aimed to include items which deal with the work on data as well as on literature because the professors explicitly mentioned those two areas. Finally four items were incorporated for both data and literature. Likewise, the Artistic dimension included three items for creative and four items for aesthetic aspects. Thus, this final version is comprised of a total of 39 items. Ten of these items are identical to the ones of the original questionnaire developed by Wentorf et al. (2015), who based his questionnaire not only on answers of scientists, but also on answers of students. To ensure the quality of the questionnaire, 92 junior scientists were asked to complete the final version. The sample of 92 junior scientists is quite limited and might require a replication study in the future; however, the reliabilities were satisfactory, as shown in Table 4.

Table 4. Number of items and corresponding reliabilities. 


\begin{tabular}{|l|l|l|}
\hline & \multicolumn{2}{|l|}{ Optimised questionnaire } \\
$N=92$
\end{tabular}

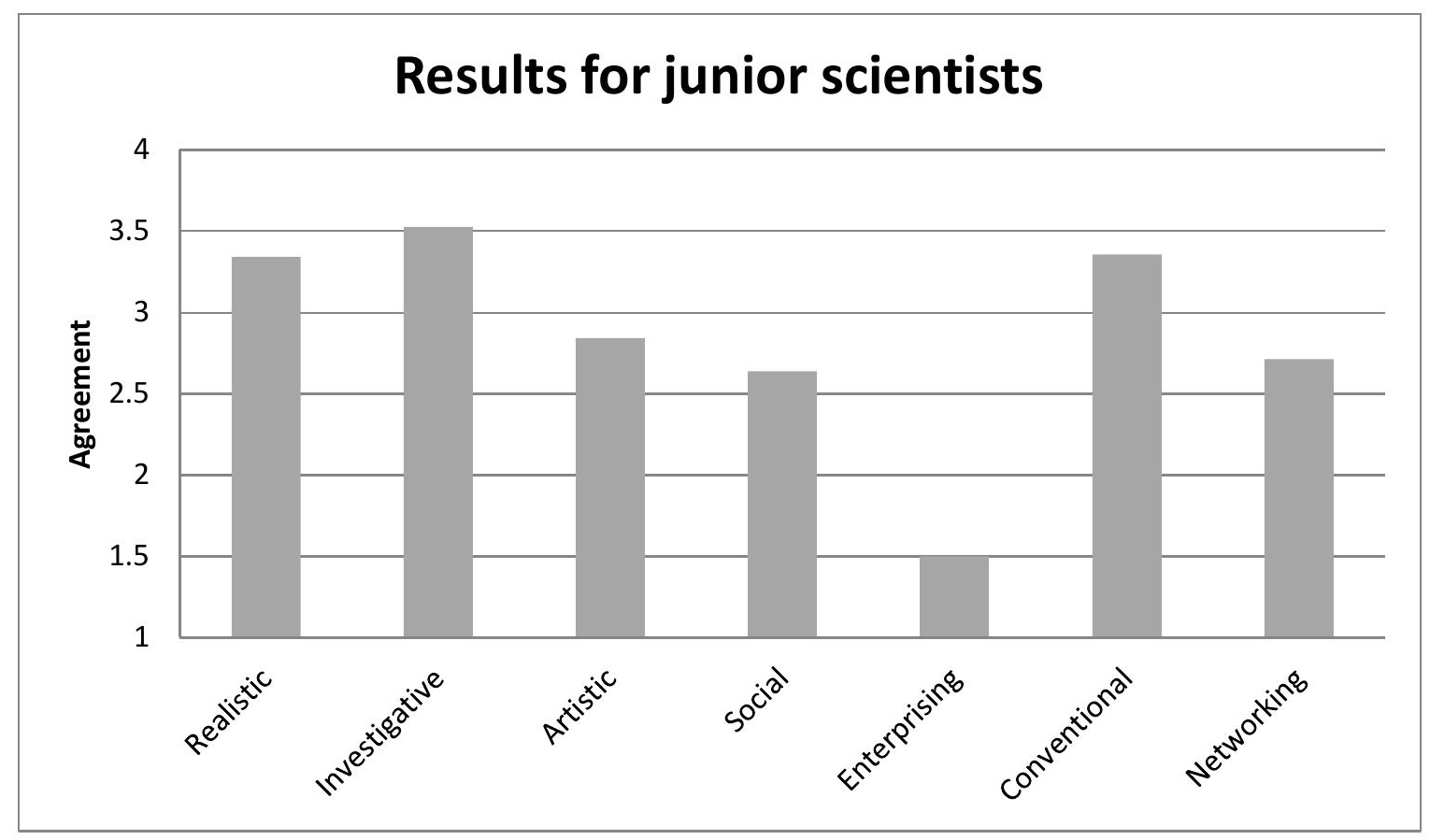

Figure 1. Self-perception of young scientists $(N=92)$ regarding scientific activities they regularly conduct.

The average values (Figure 1) for all dimensions are higher than 2.5, except for the dimension Enterprising with a value of 1.5. This may be because the professors, not the junior scientists, are responsible for the finances. We also questioned 10 professors. As expected, the resulting average value (of 3.5) increased. In addition, the average values for the other dimensions, except for the dimensions Realistic and Conventional, are higher than the average values of the junior scientists. These results are discussed below and were used for the video development in Study 2 .

\section{Discussion}

Except for the dimension Enterprising, the average score of the junior scientists' answers are higher than 2.5 (Figure 1). The low average score of the dimension Enterprising may result because it is not the task of junior scientists to plan finances (Figure 1). In comparison, the average score of the professors' answers, concerning all dimensions, is nearly 3 or higher. Thus, the scientists agree that the chosen activities are typical everyday activities for scientists. The dimensions Realistic and Conventional were scored the lowest by the professors in contrast to the junior scientists, who scored these dimensions the highest. These dimensions include stereotypical activities such as "conducting experiments" or "writing down measurement data", 
which are typical activities carried out by junior scientists and no longer professors. Typical activities of professors averaged higher, for example, on the dimensions Social ("supervising university students"), Artistic ("developing new research ideas"), Networking ("working together in interdisciplinary projects") and Enterprising ("ensuring funds for research projects").

\section{Sub-study 2: Development and validation of videos}

\section{Development of video vignettes}

Videos were planned based on the qualitative and quantitative results shown in Study 1. First, considerations regarding the contents of the videos were necessary. Activities covering all RIASEC+N dimensions had to be integrated to convey insight into the everyday life of a scientist. In order to integrate the videos into the respective experimental stations, the videos and the stations of the student laboratory needed to match content-wise. It was decided to use four individual projects the CRC scientists were currently working on as plotlines for the four videos since the experiments of the student laboratory were developed in cooperation with the scientists of the CRC.

The CRC topics or rather the topics of the experimental stations in the student laboratory are nanoscience and switchable molecules. The student groups mostly worked independently but were accompanied by one supervisor at each station. There the students were first given a short introduction to the topic before they watched the video. They conducted the experimental part after watching the video.

Overall, four video vignettes of 5-10 minutes in length were planned and subsequently recorded at the different scientific faculties. Scientists of the CRC were chosen as actors presenting their own work. The structure of all four videos is identical. In the beginning the title, the chosen institute and the main actor are shown. Afterwards comes the story with different activities and conversations. Scenes which only show activities without conversation are supported by subtitles.

\section{First video}

The experiment station for which the first video was developed focuses on a switchable molecule ${ }^{1}$ named spiropyrane. The video is set in the department of organic chemistry and shows a synthesis of spiropyrane in a laboratory, starting after a few failed synthesis attempts. Following the preparation of the synthesis, the chemist has to wait for the reaction to finish, cleans the product, conducts measurements and finally analyses the data he acquired. This time, the synthesis is successful. The typical activities of scientists, covered in this video, are part of the dimensions Realistic, Conventional and Investigative as shown in Figure 2. After watching the video, the students received a sample of spiropyrane to conduct switching tests with different light sources and different solvents.

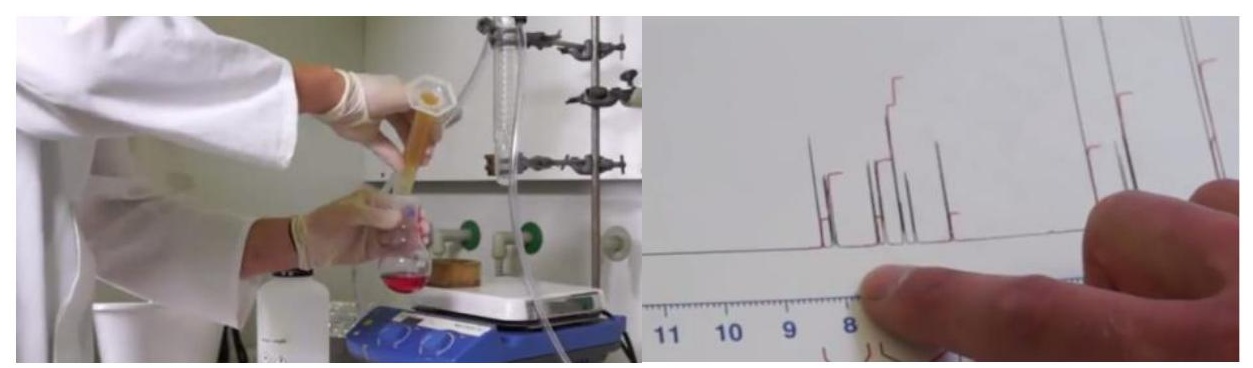

Figure 2. Activities of scientists from video one. Left: Preparation of the synthesis of spiropyran (dimension Realistic). Right: Analysing the resulting data (dimension Investigative). 
${ }^{1}$ Footnote: Switchable molecules are molecules that can be reversibly switched by external stimuli like heat or light.

\section{Second video}

The second experiment station presents different everyday products containing switchable molecules. The corresponding video vignette shows a collaboration between the chemist of the first video and a material scientist. The material scientist receives a sample of spiropyrane from the chemist and mixes it with a polymer to obtain a switchable plastic product. After testing which stimuli are able to switch the product, the material scientist designs a poster with the results to present to other scientists at a conference. These activities cover the dimensions Networking, Realistic and Artistic (Figure 3). Following the video, the students received different switchable, everyday products, such as glasses which automatically darken when exposed to sun- (UV-) light, or cups which change colour when heated.

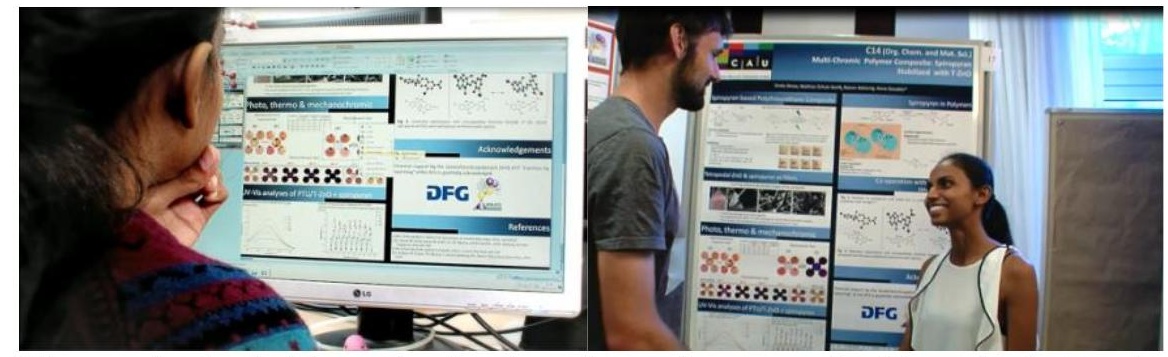

Figure 3. Activities of scientists from the second video. Left: Designing of a scientific poster (dimension Artistic). Right: Presentation of the results to another scientist (dimension Networking).

\section{Third video}

The next experiment station deals with computer simulations and its corresponding video takes place at the pharmaceutical institute. The video starts with a conversation between a professor and a doctoral student about the financial situation of their research project. Afterwards, the junior scientist supervises a master's student and gives a short introduction to biomolecule modelling software. Finally, a lecture about further simulations is shown. These activities match the dimensions Social and Enterprising as shown in Figure 4. After watching the video, the students were able to simulate a protein structure with the same software.

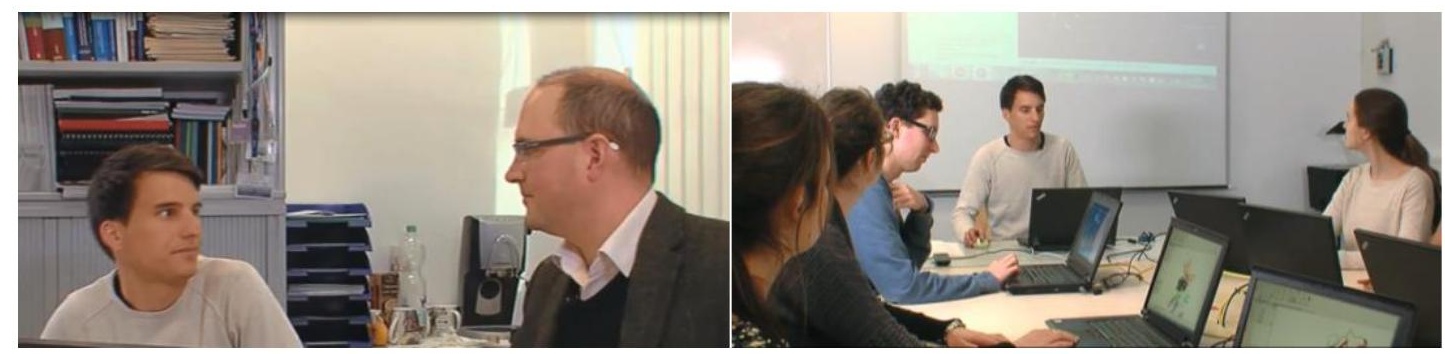

Figure 4. Activities of scientists from the third video. Left: talking about the funds of a research project (dimension Enterprising). Right: giving a seminar for university students (dimension Social).

\section{Fourth video}

The last experiment station with an integrated video involves nano-scaled surface measurements conducted with an atomic force microscope (AFM) and a scanning tunnelling microscope (STM). The corresponding video takes place in the physics institute and follows the most important steps of a research project, including measurements, repeating failed attempts and finally writing and publishing the results in cooperation with chemists who synthesised the measured compound. Covered dimensions include Conventional, Networking, 
Investigative and Realistic (Figure 5). After watching the video, the students themselves conducted measurements with the AFM and STM.

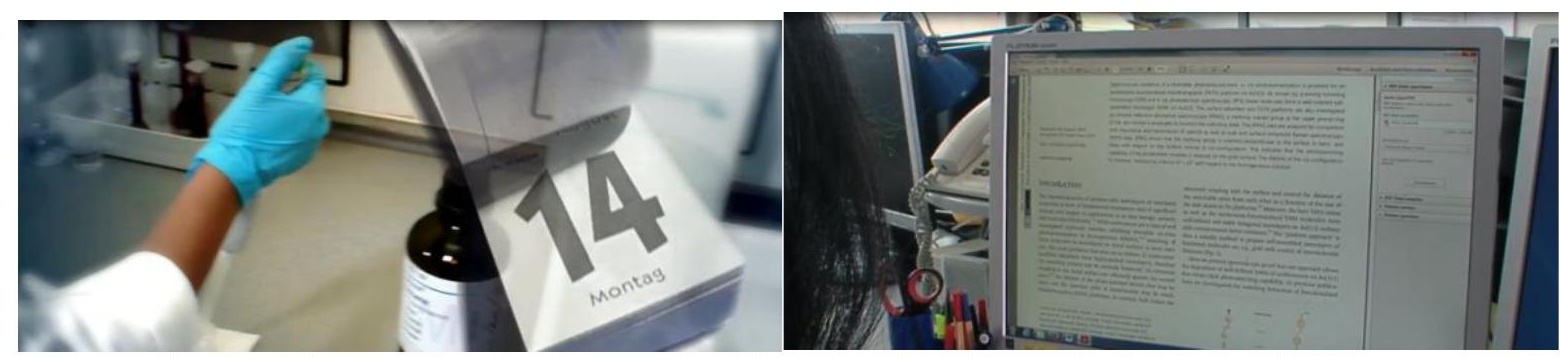

Figure 5. Activities of scientists from the fourth video. Left: repeating measurements (dimension Conventional). Right: reading scientific literature (dimension Investigative).

Validation of video vignettes

A Think-Aloud- and an interview-study for the optimisation and validation of the video vignettes was carried out. Thereby 96 students (31 girls and 65 boys) who visited the student laboratory with their teacher for one day were interviewed. They were divided into groups of two to four students (19 groups of two students; 18 groups of three students and one group of four students). These students were from 8 different secondary school classes, ranging from grade 10 to 13, and were interviewed during their laboratory participation. In the Think-AloudStudy the students were invited to communicate all of their thoughts while watching the video. The study was conducted without any (content) specific questions or focus. By doing so, we aimed to determine what details the students focused on, as well as ways to optimise technical details, such as placement of music or scene length. Furthermore, the students mentioned chemistry specific details, such as names of substances and, as we had hoped, activities of scientists. An interview was conducted after showing the videos. The main question was: "Which activities were conducted by the scientists in the video?" This question was designed to determine all activities the students had noticed.

Results: Think-Aloud- \& Interview-Study

The following graphs show how many student groups mentioned the activities within the ThinkAloud and interview study. Please be aware that we considered the comments of the student groups and not the responses of every single student, as most of the students would not repeat the answers of their groupmates. As can be seen in Figure 2, all nine groups of students noticed Realistic and Investigative activities in the first video. Six groups also mentioned the dimension Conventional. Thus, all activities we had intended to be seen in the video were indeed perceived by at least some of the students.

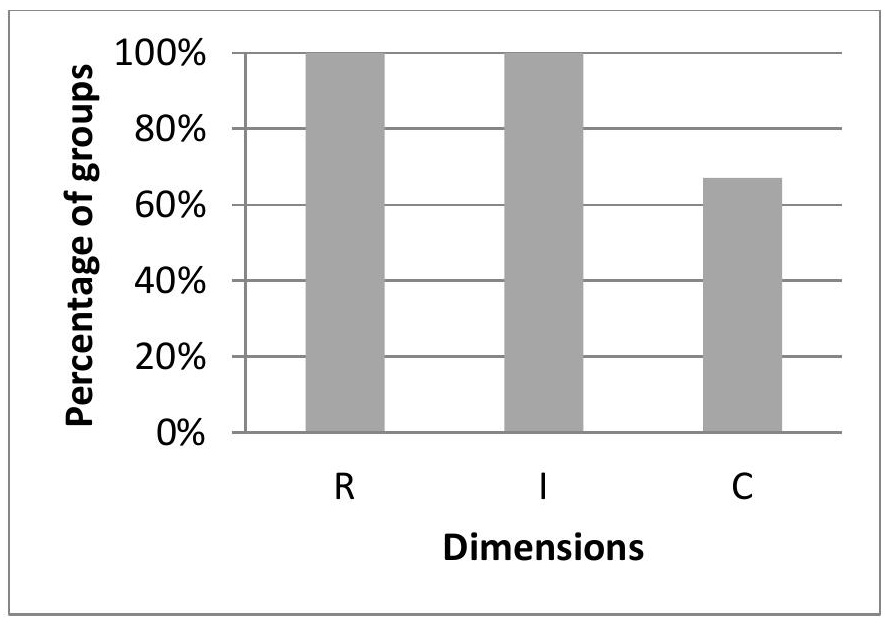


Figure 6. Percentage of student groups (nine groups) who noticed the activities of the dimensions Realistic, Investigative and Conventional in the first video within the Think-Aloud and interview study. In grey: activities which were intended integrated. All other dimensions were not mentioned by the student groups.

In Video 2, the dimensions Networking, Realistic and Artistic (in green) were explicitly considered. Side activities belonging to other dimensions were also present in the different videos since it is unauthentic to present some of the selected dimensions without putting them into a broader context. For instance, the dimension Realistic that was planned as a focus dimension in Video 1, also had to be included in this video as background context for the other dimensions. In this case, eight out of nine groups perceived the category Realistic and all groups perceived the categories Artistic and Networking. Furthermore, three groups considered activities of the category Investigative and two groups considered activities of the categories Social and Conventional, which were not explicitly integrated in Video 2.

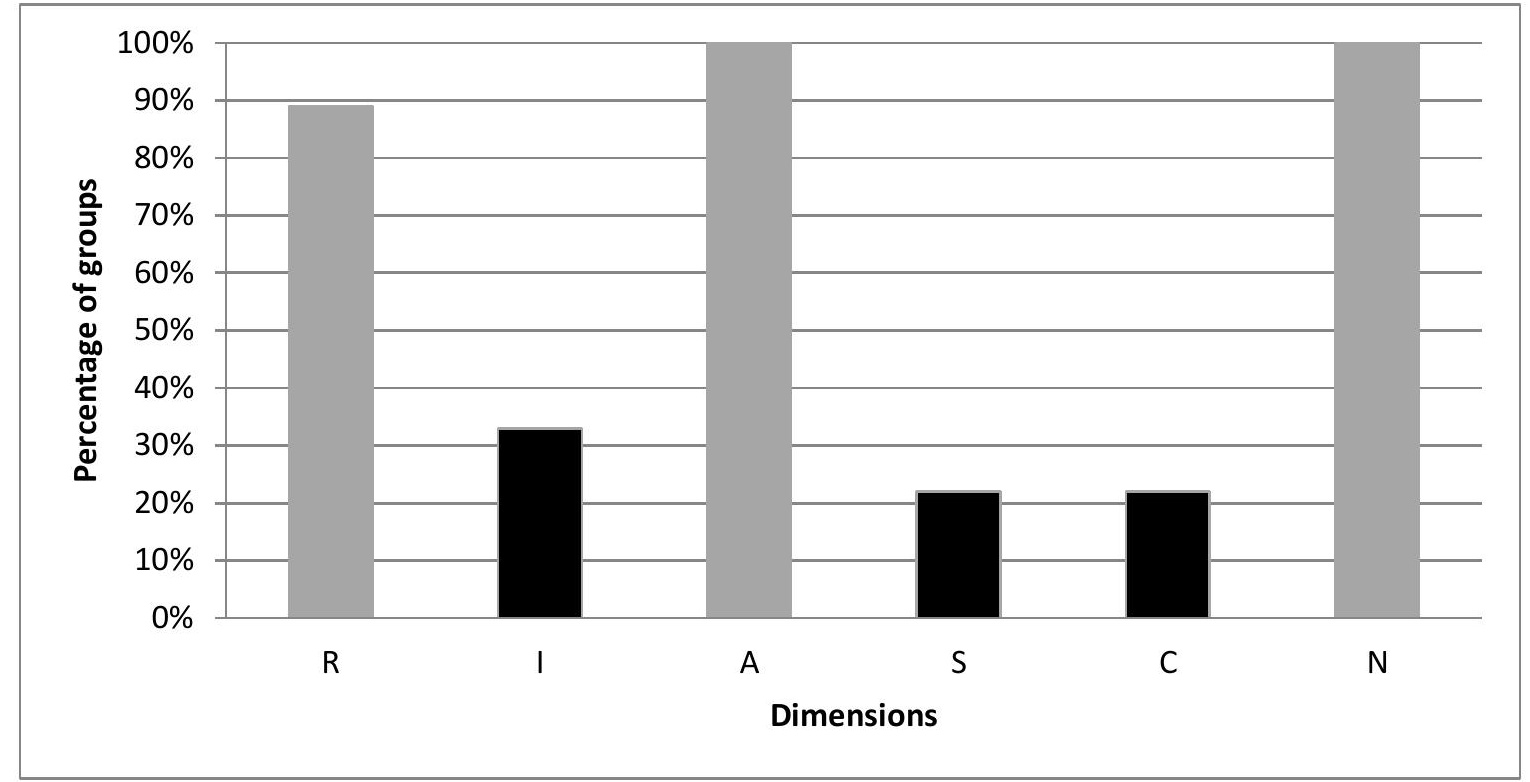

Figure 7. Percentage of student groups (nine groups) who noticed the activities of the dimensions Realistic, Investigative, Artistic, Social, Conventional and Networking. In grey: activities which were intended integrated; in black: activities which were not explicit integrated in Video 2. Enterprising were not mentioned by the student groups.

Investigative: "[I saw] that she was evaluating everything and writing it down."

"[After that] she evaluated the experiment results also using her computer program; we saw many statistics[, diagrams and pictures]."

Social: "That was a lecture."

"I think that was a lecture from a professor about spiropyrane."

Conventional: "[I can see] that she is verifying her experiments or something like that."

To validate Video 3, eleven groups of students were questioned and all groups perceived the categories Enterprising and Social. These are the two categories explicitly shown in Video 3. Furthermore, three groups perceived the category Networking, while each of the categories Realistic and Investigative was perceived once. 


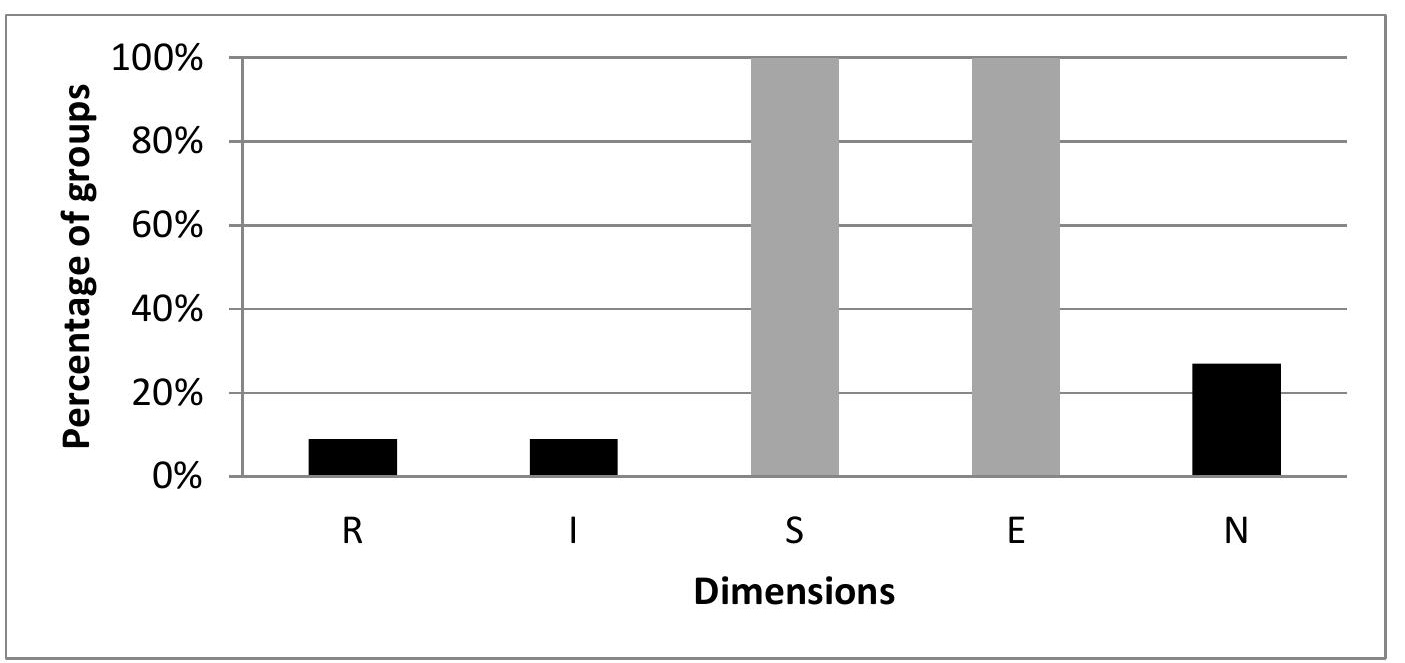

Figure 8. Percentage of student groups (eleven groups) who noticed the activities of the dimensions Realistic, Social and Enterprising. In grey: activities which were intended integrated; in black: activities which were not explicit integrated in Video 3. All other dimensions were not mentioned by the student groups.

Realistic: "He conducts experiments by himself."

Investigative: ".. and writes a thesis."

Networking: ".. and then he met his colleague and said that he is satisfied that he got an order."

Video 4 was developed to cover the categories Realistic, Investigative, Conventional and Networking. All nine groups perceived the category Realistic and Investigative, eight groups the category Conventional and seven groups perceived the category Networking. Only the category Artistic, mentioned by one group, was not especially recognised.

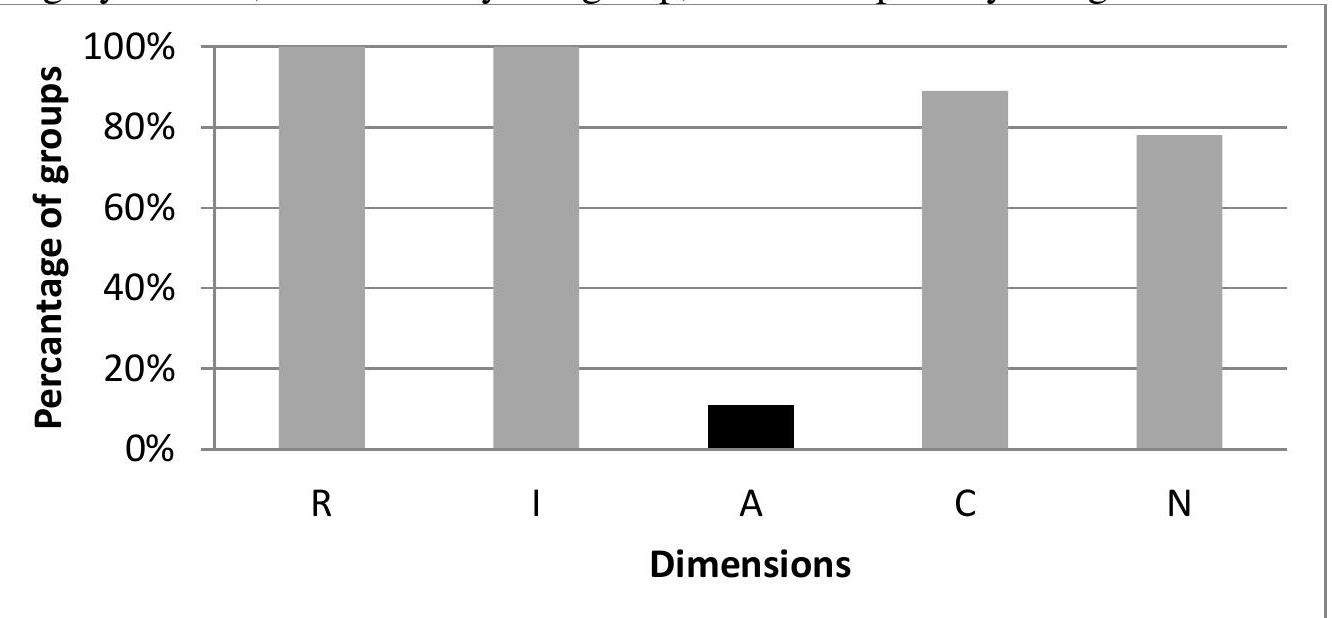

Figure 9. Percentage of student groups (nine groups) who noticed the activities of the dimensions Realistic, Investigative, Conventional and Artistic. In grey: activities which were intended integrated; in black: activities which were not explicit integrated in Video 4 . All other dimensions were not mentioned by the student groups.

Discussion

During the video development, we aimed to include each RIASEC+N dimension. The results of the video validation show that all dimensions were detected at least $67 \%$ by the students. Furthermore, the students noticed only a few activities which were not explicitly integrated in the videos. For instance, four groups detected activities of the Investigative dimension in Video 2, which had not been explicitly included. The reason for this is that the students confused "designing a poster", which is an activity of the dimension Artistic, with "evaluating data on 
the computer". Furthermore, two groups mentioned activities belonging to the dimension Social, confusing a scientist giving a scientific talk to other scientists (dimension Networking) with a professor giving a lecture to university students (dimension Social). Other activities not specifically shown in the videos weren't detected by more than one group and will be treated as outliers. Overall the realistic (hands-on) activities such as performing measurements or experiments were easily recognised by the students - in stark contrast to the activities of the dimension Conventional, such as waiting for reactions.

\section{Additional hints for video development}

Some aspects are listed in this section which in our experiences from our study, are generally important for development and implementation of authentic science videos for students. These aspects originate from the video shoot itself or through feedback by students. In our case, the aim of the videos was promotion of the perception of authenticity via typical scientific activities. Other less important aspects should not distract from the main aspects. The following hints should be helpful as well:

First, appropriate actors should be selected. Should you choose professional actors or rather authentic amateurs? Either can be appropriate, depending on your focus. What kind of appearance, gender, age, pronunciation and voice should they have to be suitable for the shown situation? In our case, some students made remarks about the pronunciation and the acting performance of the scientists in the videos, but we preferred authenticity rather than professional acting. We chose scientists and had better results when they could freely talk about the content rather than having a predefined text. However, they had to be instructed not to use too many uncommon technical terms. The next aspect is to write a script with chosen background music and locations, different perspectives, possible animations, duration of the video as a whole and of each scene, equipment and the content of the exchange. In this regard, we collected the following experiences: Background noise and music should not be too loud and the music should fit to the situation. Music-only scenes should not be too long. Animations are often perceived positively by the students. Planning requires enough time for filming each scene in which perspectives are necessary for the final cut. Which perspective should be chosen in general? For example, if someone explains something, maybe it is useful to address the audience directly, and for an authentic video it is useful to film in from the "outside" as in movies for example. The length of an introductory video is critical - for example, videos with a duration of four to ten minutes were intently followed by the students, but videos longer than that were too long. Last but not least, logical relationships and the useful embedding into the learning situation were very important for the students.

\section{Overall Conclusion}

In order to be able to develop authentic videos we had to determine the typical activities of scientists and if these activities could be assigned to the RIASEC+N dimensions. Based on the results, scientific videos have been developed and, subsequently, these videos have also been validated.

Activities, distributed over all of the RIASEC $+\mathrm{N}$ dimensions, were found and categorised through interviews with scientists. The activities of all dimensions were used for the development of the questionnaire and subsequently explicitly integrated into the four videos. A closer look into the results of the quantitative and qualitative questioning shows that it could be possible to refine the RIASEC $+\mathrm{N}$ dimensions into specific sub dimensions. For example the dimension Investigative can be split into the sub dimensions literature and data or the dimension Artistic into aesthetic and creative aspects. Furthermore, the (hands-on) activities of the dimension Realistic were very easily recognised by the students in contrast to the meticulous 
and administrative activities of the dimension Conventional. The reason, therefore, could be that it is easier to show and to identify the Realistic activities through videos than activities of the dimension Conventional. But subsequently, one could assume that students who saw all four videos will recognise all of the different fields of activities, bringing their image of an authentic scientist closer to reality. They got to know activities of scientists which were new to them, for instance, that scientists have to publish and present their results. In this way, it is possible to convey a huge spectrum of different scientific activities with the aim to expand the stereotypical images of scientists to an authentic/realistic image of scientists. While the videos only portray specific topics, the activities themselves are not bound to any subject, since we asked multiple scientists from different fields if they agree with the chosen activities; which they did. Nevertheless, we cannot be sure that we took into consideration absolutely all typical activities of scientists.

In conclusion, a general overview for authentic scientific activities was achieved through the production of video vignettes and the students were able to recognise all of the explicitly intended activities.

\section{Perspectives}

We can use the questionnaire the scientists used to ask students to answer further questions about students' views on scientific activities. This can help measure in a pre/post testing, before and after they visit the student laboratory, and whether or not watching the videos in the student laboratory has any effect on the students' viewpoints on scientists' activities. To only measure the effects of the videos, the questionnaires could be used to compare students who visited the laboratory with students who, also watched the videos. This way one can investigate whether the students watching the videos will be less susceptible to stereotypical images of scientists than the group who didn't watch the videos. Furthermore, the students' answers can also be compared to the answers the professors and junior scientists gave to investigate if watching the videos is helpful to align students' view of scientists' activities closer to that of the actual scientists. The questionnaire could also be repeated at a later date to measure the long-term effect of the videos. It is also possible to integrate a combination of videos and experiments into a classroom situation to determine the effect of the student laboratory or rather the different learning environments. Finally, it could clarify if the videos have further effects on for example the students' perceptions regarding the chosen scientific actors.

\section{Acknowledgement}

The authors would like to thank all school students and scientists that participated in the study. We would also like to thank the German Research Foundation for funding the Outreach project of the Collaborative Research Centre 677.

\section{References}

Affeldt, F., Weitz , K. , Siol, A., Markic, S., and Eilks, I. 2015. „A Non-Formal Student Laboratory as a Place for Innovation in Education for Sustainability for All Students." Education Sciences 5: 238-254. DOI:10.3390/educsci5030238

Archer, L., DeWitt, J., and Wong, B. 2014. "Spheres of influence: what shapes young people's aspirations at age 12/13 and what are the implications for education policy?" Journal of Education Policy 29 (1): 58-85. DOI: 10.1080/02680939.2013.790079 
Armstrong, P. I., Day, S. X., McVay, J. P., and Rounds, J. 2008. "Holland's RIASEC model as an integrative framework for individual differences." Journal of Counceling Psychology 55 (1): 1-18.

Braund, M., and Reiss, M. 2006. "Towards a More Authentic Science Curriculum: The Contribution of Out-of-School Learning." International Journal of Science Education 28 (12): 1373-1388. http://dx.doi.org/10.1080/09500690500498419

Cohen, J. D., Jones, M. W., and Smith, S. 2017. "Preservice and Early Career Teachers' Preconceptions and Misconceptions About Making in Education" Journal of Digital Learning in Teacher Education 34 (1): 31-42. DOI: 10.1080/21532974.2017.1387832

Coll, R. K., and Paku, L. 2011. "The influence of experiential learning on Indigenous New Zealanders' attitude towards science." In: Attitude research in science education: Classic and contemporary measurements, edited by I. M. Saleh and M. S. Khine, 219-238. Charlotte: IAP.

Dierks, P. O., Höffler, T., and Parchmann, I. 2014. "Profiling interest of students in science: Learning in school and beyond." Research in Science \& Technological Education 32 (2): 97-114. doi:10.

1080./02635143.2014.895712

Edelson, D. C. 1998. "Realizing authentic science learning through the adaptation of scientific practice." In International Handbook of Science Education, edited by B. J. Fraser and K. G. Tobin, 317-331. Dordrecht: Kluwer.

Edelson, D. C., Gordin, D. N. and Pea, R. D. 1999. "Addressing the challenges of inquiry-based learning through technology and curriculum design." Journal of the Learning Sciences 8 (3/4): 391-450.

Euler, M. 2005. "Students as scientists: Informal learning in science labs." [In German: Schülerinnen und Schüler als Forscher: Informelles Lernen im Schülerlabor.] Naturwissenschaften im Unterricht Physik 16 (90), 4-12.

Flaig, M., Simonsmeier, B. A., Mayer, A.-K., Rosman, R., Gorges, J., and Schneider, M. 2018. "Conceptual change and knowledge integration as learning processes in higher education: A latent transition analysis." Elsevier 62: 49-61.

Glowinski, I., and Bayrhuber, H. 2011. "Student labs on a university campus as a type of out-of-school learning environment: Assessing the potential to promote students' interest in science." International Journal of Environmental \& Science Education 6 (4): 371-392.

Godin, B., and Gingras, Y., 2000. "What is scientific and technological culture and how is it measured? A multidimensional model." Public Understanding of Science 9: 43-58.

Goldman, S. R., Petrosino, A., Sherwood R. D., Garrison, S., Hicken, D. T., Bransford, J. D., and Pellegrino, J. W. 1994. „Multimedia Environments for Enhancing Science Instruction.” In: TechnologyBased Learning Environments, edited by Vosniadou S., De Corte E., Mandl H., 137: 89-96. NATO ASI Series (Series F: Computer and Systems Sciences). Springer, Berlin, Heidelberg.

Hannover, B., and Kessels, U. 2002. "Challenge the science-stereotype. Der Einfluss von TechnikFreizeitkursen auf das Naturwissenschaften-Stereotyp von Schülerinnen und Schülern." Zeitschrift für Pädagogik 45: 341-358.

Holland, J. L. 1997. "Making vocational choices: A theory of vocational personalities and work environments." 3rd ed. Edessa, FL: Psychological Assessment Resources.

Holland, J. L. 1963. "Explorations of a theory of vocational choice and achievement: II. A four-year prediction study." Psychological Reports 12: 547-594.

Höttecke, D. 2004. “Student Ideas Regarding „Nature of Science.“ [In German: Schülervorstellungen über die "Natur der Naturwissenschaften".] In: Teaching and Learning about the Nature of Science. [In 
German: Lehren und Lernen über die Natur der Naturwissenschaften], edited by C. Hößle, D. Höttecke \& E. Kircher, 264-277. Baltmannsweiler: Schneider Verlag Hohengehren.

Laherto, A., Tirre, F., Kampschulte, L., Parchmann, I., and Schwarzer, S. 2018. „Scientists“ perceptions on the Nature of Nanoscience and its public communication." Problems of Education in the 21.st Century 76 (1): 2538-7111.

Lee H. S. \& Butler Songer, N. 2003. „Making authentic science accessible to students.” International Journal of Science Education 25 (8): 923-948.

Mayring, P. 2008. "Qualitative Content Analysis.” [In German: Qualitative Inhaltsanalyse. Grundlagen und Techniken.] $10^{\text {th }}$ ed. Weinheim und Basel: Beltz Verlag.

Pea, R. D. 1994. „Seeing what we build together: distributed multimedia learning environments for transformative communications." Journal of the Learning Sciences 3 (3): 285-299.

Popli, R. 1999. "Scientific literacy for all citizens: different concepts and contents." Public Understanding of Science 8: 123-137.

Posner, G. J., Strike, K., A., Hewson, P. W., Gertzog, W. A. 1982. “Accommodation of a scientific conception: Toward a theory of conceptual change.” Science Education 66 (2): 211-227.

Schmidt, I. ,Di Fuccia, D., and Ralle, B. 2011. "Out-of-school learning - Expectations, experiences and effects from the viewpoint of teachers and school administrators." [In German: Außerschulische Lernorte - Erwartungen, Erfahrungen und Wirkungen aus der Sicht von Lehrkräften und Schulleitungen.] Mathematisch Naturwissenschaftlicher Unterricht 64 (6): 362-369.

Setterlund, M. B., \& Niedenthal, P. M. (1993). ““Who am I? Why am I here?” Self-esteem, self-clarity, and prototype matching." Journal of personality and social psychology 65 (4): 769.

Solomon, J., Scott, L., and Duveen, J. 1994. "Pupils' images of scientific epistemology." International Journal of Science Education 16 (3): 361-373.

Solomon, J., Scott, L., and Duveen, J. 1996. "Large-scale exploration of pupils' understanding of the nature of science." Science Education 80 (5): 493-508.

Tintori A. 2017. "The most common stereotypes about science and scientists: what scholars know." In: Turn on the light on science, edited by Tintori A. \& Palomba R. London: Ubiquity Press. DOI: https://doi.org/10.5334/bba.b

Ulriksen, L., Madsen, L.M., and Holmegaard, H.T. 2010. "What do we know about explanations for drop out/opt out among young people from STM higher education programmes?" Studies in Science Education 46 (2): 209-244. doi: 10.1080/03057267.2010.504549

Wentorf, W., Höffler, T. N., and Parchmann, I. 2015. "Concepts of students about the activities of scientists: Perception, corresponding interests and self-efficacy expectations." [In German: Schülerkonzepte über das Tätigkeitsspektrum von Naturwissenschaftlerinnen und Naturwissenschaftlern: Vorstellungen, korrespondierende Interessen und Selbstwirksamkeitserwartungen.] Zeitschrift für Didaktik der Naturwissenschaften 21: 207-222.

Wentorf, W. 2016. "What do students think about scientists and their professions?" In: Narratives of Doctoral Studies in Science Education: Making the transition from educational practitioner to researcher, edited by Simon S., Ottander C. and Parchmann, I., 95-105. Routledge, London \& New York.

Woods-McConney, A., Oliver, M. C., McConney, A., Schibeci, R., and Maor, D. 2013. "Science Engagement and Literacy: A Retrospective Analysis for Indigenous and Non-Indigenous Students in Aotearoa New Zealand and Australia." Research in Science Education 43 (1): 233-252. 